\title{
LA ARQUITECTURA EN EL CAMPO DE CALATRAVA (1500-1570): DE JUAN DE BAEZA Y ANTÓN EGAS A ENRIQUE EGAS EL MOZO Y MARTÍN DE ZALVILLA
}

\author{
JosÉ JAVIER BARRANQUERo CONTENTO
}

\begin{abstract}
A finales del siglo XV se inició un amplio proceso de renovación arquitectónica en los dominios de las Órdenes Militares que transformó profundamente el panorama existente. Nuestro trabajo analiza este proceso en el Campo de Calatrava entre 1500 y 1570. En este sentido, realizaremos un recorrido por las principales obras que se iniciaron durante este período en la comarca, precisando el marco cronológico en el que se desarrollaron y el nombre de los maestros que trabajaron en ellas.
\end{abstract}

Palabras clave: Campo de Calatrava; arquitectura; siglo XVI; Juan de Baeza; Antón Egas; Enrique Egas el Mozo; Lorenzo de Balbás; Pedro de Hita; Alonso de Escuderos; Martín de Zalvilla.

\section{ARCHITECTURE IN THE CAMPO DE CALATRAVA REGION (1500-1570): FROM JUAN DE \\ BAEZA \& ANTÓN EGAS TO ENRIQUE EGAS EL MOZO \& MARTÍN DE ZALVILLA}

Toward the end of the 15 th century a broad process of architectural renovation was begun in the dominions of the Military Orders, which profoundly transformed the extant panorama. This study deals with this process in the countryside denominated Campo de Calatrava between 1500 and 1570, by focusing on the main works in the region, specifying when they were built and indicating the masters who worked on them.

Key words: Campo de Calatrava; architecture; 16th century; Juan de Baeza; Antón Egas; Enrique Egas el Mozo; Lorenzo de Balbás; Pedro de Hita; Alonso de Escuderos; Martín de Zalvilla.

A finales del siglo XV se inició un proceso de renovación arquitectónica en los dominios de las Órdenes Militares que se prolongó durante buena parte del XVI y que transformó profundamente el panorama arquitectónico que podía contemplarse en ellos.

En la actualidad contamos con varios trabajos que han abordado el estudio de este proceso en los dominios de algunas órdenes, como la de Santiago ${ }^{1}$, pero todavía no existe ningún estudio de conjunto para el Campo de Calatrava. En la medida de lo posible, nuestro trabajo pretende solventar este vacío, aportando datos inéditos sobre el desarrollo de las distintas obras que se emprendieron entre 1500 y 1570 y, como no, sobre los maestros que trabajaron en ellas, aspecto este último que nos servirá para estructurar la mayor parte del análisis.

\footnotetext{
${ }^{1}$ Basten dos ejemplos al respecto: Azcárate Ristori, 1959. Molina Chamizo, 2006.
} 
El período que vamos a estudiar se caracterizará, como en el resto de Castilla, por la pervivencia de los planteamientos tardogóticos, en especial de las bóvedas de crucería, aunque el lenguaje arquitectónico irá transformándose con la incorporación de nuevos elementos estructurales y, especialmente, de los nuevos modelos ornamentales propios del Renacimiento. Durante esta etapa se reformaron, al menos, seis parroquias (concretamente, las de Almodóvar del Campo, Argamasilla de Calatrava, Manzanares, Miguelturra, Puertollano y Valdepeñas) y se construyeron otros cuatro edificios que vinieron a sumarse al panorama ya existente (la parroquia de San Pedro de Daimiel ${ }^{2}$, y otros tres en Almagro: el monasterio de Nuestra Señora de la Asunción, la parroquia de la Madre de Dios y el convento de los dominicos).

La actividad constructiva que se desarrolló propició la llegada de un grupo de maestros relativamente amplio en el que tendrían cabida nombres como Juan de Baeza, Lorenzo de Balbás, Pedro de Hita o Alonso de Escuderos, maestros todos ellos que trabajaron fundamentalmente durante el primer tercio del siglo, o personajes como Martín de Zalvilla, Martín de Arteta y Domingo de Uberoaga, documentados a partir de mediados del mismo. Sin embargo, los artífices que tuvieron más influencia y mayor peso específico en la comarca fueron otros dos maestros que, además, eran miembros de la misma familia: Antón Egas y, su sobrino, Enrique Egas el Mozo.

\section{La parroquia de Valdepeñas y Juan de Baeza}

Aunque no tenemos referencias documentales directas sobre el inicio de las obras, si tenemos en cuenta el estado en el que se hallaban a principios del siglo XVI parece lógico pensar que la iglesia de Valdepeñas fue el primer edificio que se reformó en la comarca. La iglesia, iniciada probablemente en el último tercio del siglo $\mathrm{XV}$, responde al característico modelo de iglesia de una sola nave rematada por un ábside poligonal de tres lados, aunque el proyecto original sufrió importantes transformaciones con la construcción de dos capillas en el lado del evangelio. El nombre del maestro que se encargaba de la obra aparece mencionado en la visita que realizó don Fernando de Córdoba a la iglesia en 1519. Según consta en el documento, la reforma estaba prácticamente terminada ya que solo faltaba por hacer el último tramo de la nave. El testimonio de don Fernando es bien claro al respecto al afirmar que pues la obra de la dicha yglesia tiene tan buen fundamento y esta en tal estado que con ayuda de Nuestro Señor se hara presto la capilla questa començada para que la yglesia quede çerrada e desenbargada de lo viejo questa por derribar ${ }^{3}$. La única referencia al maestro que dirigía las obras aparece a propósito de un cambio que debía realizarse en el altar mayor. Al parecer este elemento estaba demasiado bajo por lo que el tabernáculo que albergaba la imagen que había sobre él quedaba desproporcionado. Ante esta situación, don Fernando dio çierta forma a Juan de Baeça el maestro que haze la yglesia e se hizo una traça con su paresçer para quel dicho altar e las gradas del se alçen de manera que la sacristania pueda estar debaxo pues que no ay otro lugar conviniente e dispuesto para ella ${ }^{4}$. Por desgracia, la referencia al maestro es demasiado tardía y también muy escueta por lo que no podemos saber si estuvo al frente de las obras desde el comienzo y, mucho menos, si diseñó el proyecto.

\footnotetext{
${ }^{2}$ El documento que daba permiso para levantar el edificio se redactó el 10 de febrero de 1542. Provisión real concediendo licencia para construir otra parroquia en Daimiel en la plaza del barranco, 10 de febrero de 1542, Archivo Histórico Nacional, Madrid (AHN), Órdenes Militares, Archivo Histórico de Toledo, legajo 39768, sin foliar (sf).

${ }^{3}$ Traslado de la visita realizada por don Fernando de Córdoba a la iglesia parroquial de Valdepeñas en febrero de 1519, 17 de marzo de 1519, AHN, Órdenes Militares, Archivo Histórico de Toledo, legajo 44339, sf.

4 Traslado de la visita realizada por don Fernando de Córdoba a la iglesia parroquial de Valdepeñas en febrero de 1519, 17 de marzo de 1519, AHN, Órdenes Militares, Archivo Histórico de Toledo, legajo 44339, sf.
} 


\section{La influencia de la familia Egas: Antón Egas y Enrique Egas el Mozo}

Aunque a lo largo del siglo XVI trabajaron un buen número de maestros en el Campo de Calatrava, lo cierto es que el desarrollo de la arquitectura en la comarca está presidido por la familia Egas y Antón Egas es el primer miembro de la saga del que tenemos noticias. Su presencia en la zona, que tendría importancia por sí misma, resulta especialmente relevante por dos motivos; en primer lugar porque realizó las trazas del edificio más importante que se levantó en la comarca durante este período, el conjunto formado por el Hospital de la Misericordia y el monasterio de Nuestra Señora de la Asunción; y en segundo porque sus gestiones propiciaron la llegada de su sobrino, Enrique Egas el Mozo, a la comarca. Este personaje, del que hasta ahora no teníamos demasiadas referencias documentales, comenzó su carrera en la zona haciéndose cargo de la fábrica del hospital y del monasterio durante el mes de agosto del año 1530, y a la postre terminó convirtiéndose en el maestro más importante del momento, acaparando la dirección de varias obras en el Campo de Calatrava.

El conjunto formado por el hospital y el monasterio que acabamos de mencionar surge como consecuencia de la modificación de la disposición testamentaria del Comendador Mayor de Calatrava, Don Gutierre de Padilla. Este miembro de la orden decidió fundar a su muerte un gran hospital en la villa de Almagro que comenzó a construirse en 1519. Hasta el momento no se sabía qué maestro había diseñado este edificio pero, gracias a la documentación que hemos consultado, podemos afirmar que la traza fue realizada por Antón Egas. Las referencias que nos han permitido determinar la autoría aparecen en las diligencias que se realizaron a petición de Catalina Álvarez, mujer del que fue aparejador de la obra durante varios años, Lorenzo de Balbás, para cobrar el salario de su difunto marido que, precisamente, había muerto trabajando en ella.

El proyecto tuvo que hacer frente desde el principio a numerosos problemas, relacionados en no pocas ocasiones con la falta de pericia de los maestros que se escogieron para levantar su fábrica. Sin ir más lejos, los oficiales que comenzaron a realizar los cimientos no supieron o no quisieron seguir las indicaciones de Antón Egas y cometieron graves errores de cálculo. Los fallos eran tan evidentes que frey Juan de Inestrosa mandó parar las obras y envió una carta a Antón Egas, que estaba ocupado trabajando en el Hospital de Santa Cruz, solicitándole un maestro que dirigiese la obra. A pesar de lo dispuesto, los trabajos volvieron a emprenderse porque, unos días después, frey Bernardino de Lucio volvió a comprobar que los maestros seguían equivocados y, para evitar males mayores, ordenó paralizar las obras asy en el hazer como en el deshazer, redactando una segunda misiva dirigida también al maestro Egas que acompañó a la escrita anteriormente por frey Juan 5 .

Antón Egas pensó que Lorenzo de Balbás, maestro que en esos momentos se encontraba trabajando en unas capillas en la yglesya de Talavera, era la persona idónea para dirigir la fábrica a pie de obra. Lorenzo se hizo cargo de la fábrica, pero no como maestro sino como aparejador que trabajaba bajo la dirección y supervisión del propio Antón Egas, que visitó varias veces las obras, cobrando 500 maravedís al día cada vez que lo hacía ${ }^{6}$.

El proyecto no había empezado con buen pie, pero los problemas que surgieron a la hora de interpretar los planos antes de la llegada de Balbás solo fueron los primeros de una larga serie de avatares a los que tuvo que hacer frente la fábrica. Sin ir más lejos, unos cuatro años después de iniciarse las obras, el proyecto inicial sufrió una profunda transformación que cambió radicalmente el

\footnotetext{
${ }^{5}$ Ver trascripción de la carta de Juan de Inestrosa en el apéndice documental.

${ }^{6}$ La cantidad que cobraba Antón Egas, así como su papel de maestro de la obra, aparece recogida en las declaraciones de varios testigos como Garçí González, Andrés Arias, Sebastián Rodríguez, que fue mayordomo del Hospital, o Francisco Rodríguez, cantero. Probanza realizada por frey Esteban Coello, 19 de febrero - 3 de marzo de 1537, AHN, Órdenes Militares, Archivo Histórico de Toledo, legajo 44344, sf.
} 
concepto y la fisonomía de la fundación. El proyecto era de tal envergadura que el Capítulo General de Burgos de 1523 decidió modificarlo sustancialmente. Los miembros del Capítulo redujeron el tamaño del hospital, lo dotaron con 80.000 maravedís de renta y decidieron que el resto de los bienes del Comendador Mayor se invirtiesen en la fundación de un monasterio femenino de la orden que habría de levantarse junto al hospital.

Lorenzo de Balbás tuvo bastantes problemas con su salario. Según algunos testimonios el maestro empezó cobrando tres reales al día, pero frey Juan de Inestrosa le rebajó el sueldo medio real, aunque posteriormente frey Pedro de Troya y frey Hernán Bravo de Zayas, los nuevos disponedores de la obra, volvieron a subírselo, dejándolo en la cantidad inicial. Además, los susodichos le entregaron de forma puntual otros 10.000 maravedís para que pagase el alquiler de la casa en la que vivía.

A pesar de los problemas salariales, Balbás trabajó en el hospital durante diez u once años, hasta que falleció en un accidente en la propia obra. A su muerte su puesto fue ocupado por Pedro de Hita, aunque debió hacerlo de forma interina porque al poco tiempo fue sustituido por Enrique Egas el Mozo que, como ya hemos dicho, se hizo cargo de la fábrica en agosto de $1530^{7}$. Enrique, que en esos momentos contaba tan solo con unos veintiséis años ${ }^{8}$, pudo hacerse con la dirección de la obra gracias, entre otras cosas, a la intervención de su tío. Los detalles los conocemos gracias a una carta que envió Antón Egas a su sobrino. En la misiva el maestro afirmaba que los señores disponedores se habían puesto en contacto con él por mandado del Consejo para dar horden como la obra se haga e quisyeron mi paresçer de que persona podia tener cargo de la obra e yo les he dicho la persona que soys e lo que sabeys e como podreys dar quenta de aquella obra e de otra mayor e ellos sabiendo ser vos hijo de maestre Enrrique e por lo que yo les he dicho aunque no os conosçen avran por bien de vos dar cargo de la obra e mejoraros en el partido que davan a Balbas que hera tres rreales cada dia e dos moços e por rrazon de una casa que le mandaron en que morase le dieron diez mill maravedis una vez yo tengo platicado e asentado que os den a vos diez mill maravedis de salario en cada un año e los tres rreales cada dia de trabajo e dos moços con los jornales que meresçieren e mas en el mesmo monesterio una o dos pieças en que podays estar vos e vuestra jente sy las quisyeredes.

Al hacerse cargo de la dirección, Enrique Egas tuvo que rehacer buena parte de lo levantado por Lorenzo de Balbás, situación que incidió muy negativamente en el desarrollo de las obras. Al parecer, mientras había sido aparejador de la fábrica, Lorenzo no había seguido, o no había entendido, las indicaciones de Antón Egas y se había eçedio de la traça e horden e manera que se dio por Anton Egas, cometiendo graves errores a la hora de ejecutar las obras. El propio Antón visitó la fábrica tras la muerte de Balbás y pudo ver la situación en la que se hallaba, constatando la existencia de errores que tuvo que solventar Enrique Egas el Mozo. En este sentido, Enrique declaró

\footnotetext{
${ }^{7}$ La única referencia que hemos encontrado sobre el papel que desempeñó Pedro de Hita como aparejador de la obra aparece en una de las declaraciones del propio Enrique Egas, concretamente cuando hace mención a la traza del convento precisando que quando vino como tal maeso que pidio la traça por donde se rrije el dicho Lorenço de Balbas e que le fue dada una traça la qual se truxo de casa de Lorenço de Balbas o de casa de Pedro de Hita que rresydie por aparejador a la sazon en la dicha obra. Declaración de Enrique Egas el Mozo contenida en las nuevas diligencias realizadas por frey Esteban Coello y frey Sebastián de Mera, 11 de febrero de 1538, AHN, Órdenes Militares, Archivo Histórico de Toledo, legajo 44344, sf.

${ }^{8}$ Los documentos que hemos consultado nos han permitido fijar con gran precisión la fecha de nacimiento del maestro. El 10 de diciembre de 1567 fue requerido para dar testimonio acerca de una de las obras que había diseñado, concretamente la capilla mayor de la parroquia de Argamasilla de Calatrava, y en respuesta a las preguntas de carácter general que debía contestar cualquier testigo precisó que era de edad de sesenta y tres años poco mas o menos, por lo que nuestro hombre habría nacido en torno a 1504.

9 Traslado de una carta remitida por Antón Egas a Enrique Egas el Mozo incluido en la probanza realizada por frey Esteban Coello, 19 de febrero de 1537, AHN, Órdenes Militares, Archivo Histórico de Toledo, legajo 44344, sf.
} 
que cuando llegó a la localidad pidió la traza que había utilizado Lorenzo, pero le entregaron una que no estaba firmada, por lo que no podía afirmar que hubiera excedido la diseñada por su tío, pero reconoció que en la obra había algunas cosas herradas las quales no heran hazederas por Anton Egas. El maestro precisó que había oído decir a Sebastián Rodríguez, mayordomo de las obras, que venido Anton Egas a vesitar las dichas obras despues de ser fallesçido el dicho Lorenço de Balbas que avia dicho el dicho Anton Egas que çiertas cosas que despues aca se an desecho e tornado a poner en rrazon por mandado deste testigo quel dicho Anton Egas no lo avia mandado hazer en su traça. Enrique precisó que Lorenzo de Balbás se había equivocado al ubicar el arco de la escalera del claustro y la puerta de la sala capitular; en el dormitorio situado en el segundo piso había abierto una ventana donde no debía y, además, había construido un contrafuerte en la cabecera de la iglesia que era totalmente innecesario y que además impedía el tránsito por el claustro $^{10}$. Los errores cometidos por Lorenzo no se terminaban aquí porque a juicio de Enrique también era necesario solucionar çiertas cosas que la yglesia tiene de defetos.

La siguiente referencia documental que hemos conseguido localizar en relación con el trabajo de Enrique Egas el Mozo en la fábrica del monasterio aparece en las cuentas que rindió frey Sebastián de Mera el 18 de enero de 1540 ante los miembros del Consejo de Órdenes. El documento menciona un primer libramiento, fechado el 12 de enero de 1538, por el qual pareçio que dieron y pagaron a maestro Enrrique Egas quatro myll y çiento y sesenta y siete maravedís los quales ovo de aver de un tercio de año e un mes a rrazon de a diez mill maravedis que le dan de salario en cada un año por maestro de las dichas obras quenpeçaron (sic.) a correr primero dia del mes de agosto y cumplieron postrero de diziembre de myll e quynientos y treynta e syete años ${ }^{11}$.

El pago del salario como maestro de la obra volvió a repetirse poco después, consignándose un segundo libramiento fechado el 11 de mayo de ese mismo año por el qual pareçio que dieron y pagaron a (sic.) maestro Enrrique Egas maestro de las dichas obras diez myll maravedís que los ovo de aver de su salario deste dicho año que començo a correr primero dia de enero y cumplio en fin del mes de diziembre los quales le fueron pagados por tercios del dicho año.

La cantidad que acabamos de mencionar no es la última que se abonó al maestro porque en las cuentas se incluye otro libramiento fechado el 11 de agosto de 1539 por el que se pagaron a Enrique Egas otros 3.728 maravedís por seys varas y una quarta de entablamentos para los corredores de las dichas obras a ducado cada vara y de tress quartas de basas a syete rrales (sic.) la vara $^{12}$, referencia que estaría relacionada con la construcción del claustro del monasterio.

Enrique Egas siguió ligado a su fábrica, al menos, hasta mediados de siglo. Su nombre vuelve a aparecer en la visita que realizaron al monasterio frey Íñigo de Ayala y frey Lorenzo Suárez de

${ }^{10}$ Enrique afirmó en su declaración que Lorenzo se había salido de su traça (...) espeçialmente en el arco del escalera de la caostra (sic.) prinçipal que avia dexado el gueco del dicho arco donde avia de herir la dança de arcos del corredor e ansimysmo la puerta del capitulo estava lo gueco della en donde venia a herir la otra dança de arcos no quedando donde se pudiese dar estribo a la dicha dança de arcos por rrazon que donde avia de venyr el estribo estava el gueco de la puerta e arcos sobredichos e ansimysmo se deshizo un estribo de la capilla prinçipal que caye en el rrincon de la caostra (sic.) el qual ocupava el paso della e no avia nesçesidad del en aquel lugar e ansymysmo una ventana y en el dormitorio en lo alto que ansymismo enpedia el estribo de la dança de arcos por rrazon que el gueco della venia a donde venya a herir e descansar los arcos la qual se çerro e se abrio otra en lugar mas convenyble. Declaración de Enrique Egas el Mozo contenida en las nuevas diligencias realizadas por frey Esteban Coello y frey Sebastián de Mera, 11 de febrero de 1538, AHN, Órdenes Militares, Archivo Histórico de Toledo, legajo 44344, sf.

${ }^{11}$ Cuentas del monasterio de Nuestra Señora de la Asunción presentadas por frey Sebastián de Mera ante los miembros del Consejo de Órdenes, 18 de enero de 1540, AHN, Órdenes Militares, Archivo Histórico de Toledo, legajo 43965, sf.

${ }^{12}$ Cuentas del monasterio de Nuestra Señora de la Asunción presentadas por frey Sebastián de Mera ante los miembros del Consejo de Órdenes, 18 de enero de 1540, AHN, Órdenes Militares, Archivo Histórico de Toledo, legajo 43965, sf. 
Figueroa el año 1553. Enrique no solo aparece mencionado en los pagos de las cuentas del monasterio, sino que también fue requerido por los visitadores para que diera su parecer para continuar la obra de la iglesia. A estos datos, que ya recogimos en otros trabajos ${ }^{13}$, habría que añadir una nueva referencia relacionada con la ampliación del monasterio a costa del hospital. En este sentido los visitadores ordenaron que dividiera cuatro estancias del hospital (concretamente dos pieças altas y bajas) para que parte de ellas pasaran a formar parte del monasterio ${ }^{14}$.

Gracias a su labor al frente de la fábrica del monasterio y del hospital, así como a sus referencias familiares, Enrique adquirió un prestigio que debió ser clave en el desarrollo de su carrera. Durante el segundo tercio del siglo XVI, el maestro fue requerido en numerosas ocasiones para trazar y dirigir obras en la comarca; convirtiéndose, como ya hemos dicho, en la figura más importante de la zona durante esta etapa. Sin ir más lejos, Enrique realizó una traza para la Madre de Dios en Almagro y diseñó las ampliaciones de las parroquias de Manzanares y Argamasilla de Calatrava.

La ampliación de iglesia parroquial de Manzanares incluía la construcción de una nueva capilla mayor y capillas colaterales que se an de hazer junto a ella y que avia sydo traçado por maestre Enrrique vecino de Almagro maestro de obras ${ }^{15}$. Se trataba, por tanto, de construir el ábside, el primer tramo de la nave y dos capillas colaterales que daban lugar a una iglesia con planta de cruz latina. Las obras ya se habían iniciado en 1565 , fecha en la que los visitadores aseguraron que estavan abiertos los çimientos y labrada muncha cantidad de piedra ${ }^{16}$, pero el proyecto se fraguó en la visita anterior, en 1554, cuando los visitadores anteriores constataron que el edificio se había quedado pequeño debido al crecimiento de la población y trataron el asunto con los miembros del concejo. Los visitadores de 1565, por su parte, no se limitaron a ver la fábrica sino que, además, ordenaron que desde el mes de março primero venidero se prosyga la obra comforme a la traça della y se vaya vendiendo el trigo que tiene la yglesya como se fuere haziendo la obra porque muncho dello a munchos días questa allegado de limosnas y de sus primiçias y se de notiçia de la dicha obra al señor marques de Priego comendador desta villa y se suplique a su señoria que como tiene de costunbre de favor (...) a la dicha obra para que vaya adelante. Por desgracia, no hemos encontrado muchos datos sobre la obra, tan sólo podemos precisar que la reforma de la capilla mayor estaba completamente terminada en 1577, tal y como se recoge en la visita que se realizó ese mismo año a la iglesia ${ }^{17}$.

La reforma de la parroquia de Argamasilla de Calatrava se inició en torno a 1562, ya que los testigos que declararon durante las diligencias realizadas en 1567 para conseguir el apoyo económico del Consejo de Órdenes afirmaban que la capilla se había iniciado hacía cinco años ${ }^{18}$. Al parecer los

13 Barranquero Contento, 2001: 190-192. Barranquero Contento, 2003: 310-318.

${ }_{14}$ Según consta en la visita, el seis de septiembre de 1550 se despachó una provisión real dirigida al Prior de la Coronada para que atajase de dos pieças altas y baxas del dicho hospital cierta parte dellas conforme a una traça hecha por maestro Enrrique Egas que con la dicha provision le fue entregada y que los dichos atajos los hiziese a costa de la obra del dicho hospital de muy buenas paredes gruesas para que las dichas pieças altas y baxas se metiesen y encorporasen en este dicho monesterio. Visita que realizaron frey Iñigo de Ayala y frey Lorenzo Suárez de Figueroa al monasterio de Nuestra Señora de la Asunción, 19 de mayo de 1553, AHN, Órdenes Militares, Archivo Histórico de Toledo, legajo 43132, sf.

15 AHN, Órdenes Militares, legajo 6082, sf. Este testimonio vendría a corroborar las tesis de Elena Sainz y Enrique Herrera que también adjudicaron la autoría del proyecto a Enrique Egas el Mozo, aunque sin aportar ninguna referencia documental. Sainz Magaña y Herrera Maldonado, 1996-97: 131-132.

${ }^{16}$ Visita realizada por frey Rodrigo de Vargas y frey Bartolomé Ruiz a la parroquia de Nuestra Señora Santa María de Altagracia de Manzanares, 19 de enero de 1565, AHN., Órdenes Militares, legajo 6082, exp. 14, sf.

17 Visita realizada por don Hernando Carrillo Osorio y frey Jerónimo Treviño a la parroquia de Nuestra Señora Santa María de Altagracia de Manzanares, 25 de junio de 1577, AHN, Órdenes Militares, legajo 6084, exp. 1, sf.

${ }^{18}$ Diligencias realizadas a petición del concejo de Argamasilla de Calatrava sobre la financiación de la obra de la iglesia, 1567, AHN, Órdenes Militares, Archivo Histórico de Toledo, legajo 40680, sf. 
miembros del concejo decidieron ampliar la iglesia y, tras conseguir la correspondiente licencia de los visitadores de la orden, mandaron llamar a Enrique Egas para que realizase la traza y condiciones de la obra. Según palabras del propio maestro la reforma incluía la construcción de una capilla mayor y la caveçera que son dos capillas y la sacristia. La iglesia sigue el modelo de nave única pero, a diferencia de lo visto en Valdepeñas, el edificio no está rematado por un ábside poligonal sino por una cabecera de planta cuadrangular de menor anchura que el cuerpo de la iglesia. El proyecto, como ya hemos visto, incluía también la construcción del primer tramo del cuerpo o capilla mayor que, tal y como ocurría con el presbiterio, estaba cubierto por una bóveda de crucería.

La documentación que se ha conservado nos ofrece además una pequeña descripción de la fábrica realizada por el propio Enrique Egas. El maestro precisó que ésta tenía las paredes y estrivos de manposteria e pilares de ladrillo por la parte de dentro para el arco prinçipal e que la cruçeria y las ventanas an de ser de canteria y el caxco de las bobedas de ladrillo y yesso cubiertas de madera e teja y esto save porque ansi lo tiene ordenado y traçado ${ }^{19}$. Del testimonio brindado por el maestro no se deduce que hasta ese momento hubiera realizado labores de cantería, pero sí que ejerció como maestro de obras y que, como tal, visitó varias veces la fábrica para supervisar su desarrollo. Como es lógico, en la fábrica trabajaron otros oficiales de menor entidad y en este caso conocemos, al menos, el nombre de dos de los maestros de albañilería que comenzaron a levantar sus muros. Se trata de Miguel Sánchez de Mestanza, vecino de Argamasilla, y Francisco Serrano, vecino de Almagro.

La fábrica comenzó a costearse con las limosnas que aportaron los vecinos de la localidad pero, como en tantas ocasiones, las fuentes de financiación eran claramente insuficientes y las obras se paralizaron muy pronto por falta de dinero. A finales de 1567 se habían invertido unos 2.000 ducados y a juicio de Enrique Egas eran necesarios otros 3.500 para terminar la reforma, aunque su apreciación era notablemente inferior a lo expuesto por otros testigos, que valoraban el coste de lo que aún quedaba por hacer en 6.000 ducados. Ante la falta de recursos los miembros del concejo remitieron un escrito al Consejo de Órdenes con la intención de conseguir el apoyo económico de las dignidades que percibían los diezmos. La petición surtió efecto y el Consejo les concedió 3.000 ducados que debían ser abonados por el maestre (es decir, el propio monarca como Administrador perpetuo de la Orden), el arzobispo de Toledo y el comendador de la villa. La cantidad, que debía repartirse entre estas tres dignidades de forma proporcional a las rentas que percibían en la localidad, se abonaría de forma paulatina durante un periodo de cinco años y ésta se haría efectiva con la condición de que el concejo se comprometiera a acabar perfectamente la obra con ella ${ }^{20}$.

La figura de Enrique Egas también ha estado asociada a la construcción de otro edificio emblemático de Almagro, la iglesia de Madre de Dios. Se trata de una iglesia columnaria o hallenkirche que consta de tres naves rematadas por sendos ábsides poligonales. El cuerpo de la iglesia está dividido en cuatro tramos mediante pilares con medias columnas toscanas adosadas que sostienen los nervios de las bóvedas de terceletes que cubren el edificio. Los datos que teníamos hasta ahora sobre esta iglesia procedían básicamente del libro publicado en 1894 por un erudito de Almagro, Federico Galiano y Ortega ${ }^{21}$. Este investigador, que consultó los fondos documentales del archivo municipal, precisó la fecha de inicio de las obras y el nombre del maestro que realizó las trazas. Sin embargo, sus apreciaciones no están exentas de errores que, en buena medida, se deben

${ }^{19}$ Declaración de Enrique Egas el Mozo incluida en las diligencias realizadas a petición del concejo de Argamasilla de Calatrava sobre la financiación de la obra de la iglesia, 10 de diciembre 1567, AHN, Órdenes Militares, Archivo Histórico de Toledo, legajo 40680, sf.

${ }^{20}$ Anotación con la decisión adoptada por el Consejo de Órdenes incluida en las diligencias realizadas a petición del concejo de Argamasilla de Calatrava sobre la financiación de la obra de la iglesia, sin fecha, AHN, Órdenes Militares, Archivo Histórico de Toledo, legajo 40680, sf.

${ }^{21}$ Galiano y Ortega, 2004: 173-179.

Arch. esp. arte, LXXXVI, 341, ENERO-MARZO 2013, 15-28, ISSN: 0004-0428 
al hecho de que no leyó los acuerdos municipales, sino el resumen con el contenido de los mismos que se realizó en el siglo XVIII y que aparece encabezando el libro.

La construcción de la Madre de Dios es un ejemplo paradigmático de los problemas y retrasos que sufrieron muchos edificios por la falta de financiación. A principios del siglo XVI, Almagro contaba con dos parroquias, la de San Bartolomé, que se levantaba junto a la plaza de la localidad, y la de San Sebastián, que en esos momentos quedaba fuera del caserío de la villa. La situación de este edificio solo acarreaba inconvenientes, de ahí que los miembros del concejo decidieran trasladarla y construir una nueva dentro del casco urbano de la localidad. Los miembros del ayuntamiento remitieron la correspondiente petición al Consejo de Órdenes que aceptó la propuesta, dándoles permiso para que pudiera trasladar e hazer la yglesia de la dicha perrochia en el lugar e sytio de suso declarado y hacerla segun e de la manera e de los hedeficios que quisieredes e por bien tobieredes ${ }^{22}$. La provisión se redactó el 18 de enero de $1532 \mathrm{y}$, a juzgar por los testimonios que hemos podido recoger, la ceremonia de colocación de la primera piedra debió realizarse poco tiempo después, pero lo cierto es que las obras se paralizaron rápidamente y si avanzaron lo hicieron muy poco.

Los primeros datos que tenemos en torno a la fábrica y a los maestros que trabajaron en ella proceden de un acuerdo municipal fechado el 28 de febrero de 1546. Los miembros del concejo decidieron reanudar las obras, o al menos así se deduce de lo expresado en la documentación, y ese día rubricaron un acuerdo con Juan Navarro, cantero, para que labrase la piedra necesaria para realizar las esquinas de la iglesia. El maestro se comprometió a dar toda la piedra que fuere menester para las esquinas de la dicha yglesy (sic.) puesta al pie de la obra a çinco quartillos de plata cada vara de medir desbastada, precisando que también labraría a su costa cada vara de la dicha piedra a treynta ta (sic.) maravedis ${ }^{23}$.

El mismo día que se rubricó el acuerdo con Juan Navarro compareció ante el concejo Enrique Egas y mostro la traça que por los señores justiçia rregimiento se le encargo que hiziese para fundamento de la obra de la dicha yglesya por donde se a de hazer y continuar. El maestro recibió cuatro ducados tanto por la traza como por hacer otras cosas tocantes a la dicha obra y edefiçio ${ }^{24}$. En línea con lo anterior, los miembros del ayuntamiento adoptaron otras dos medidas encaminadas a poner en marcha las obras. En primer lugar, ordenaron a Hernando de Valenzuela, a la sazón mayordomo de la obra, que busque la cal y todas las otras cosas y materiales que fueren menester para la dicha obra ${ }^{25}$. $\mathrm{Y}$, en segundo, que trajera peones para abrir la zanja de los cimientos $\mathrm{y}$, una vez comenzada la tarea, se notificase a Gaspar Rotulo que debía construir las dos capillas colaterales de la iglesia, tal y como se había comprometido mediante un acuerdo firmado con el concejo.

Unos días más tarde, el 4 de marzo, los miembros del concejo volvieron a reunirse para hablar de la obra de la iglesia y, tras llamar tanto a Enrique Egas como a Hernando de Valenzuela, decidieron quel dicho maese Enrrique entienda en la obra de la dicha yglesya para que como maestro ques entienda en ella y se haga conforme a la traça questa hecha por el dicho maese Enrrique.

${ }^{22}$ Provisión real concediendo permiso para trasladar y construir la nueva parroquia, 18 de enero de 1532, AHN, Órdenes Militares, Archivo Histórico de Toledo, legajo 42136, sf.

${ }^{23}$ Asiento con Juan Navarro, cantero, para que de la piedra labrada para la obra de la iglesia de la Madre de Dios, 28 de febrero de 1546, Archivo Municipal de Almagro, Almagro (AMA), libro de acuerdos de 1543, caja 4, siglo XVI, fol. $206 \mathrm{v}-207 \mathrm{r}$.

${ }^{24}$ Acuerdo del concejo sobre como trajo la traza maese Enrique y lo que se mandó y asentó sobre ello, 28 de febrero de 1546, AMA, libro de acuerdos de 1543, caja 4, siglo XVI, fol. 207r. y 207v. Galiano y Ortega asoció la presentación de las trazas con el inicio de las obras cuando no fue así porque, como dice el texto, el plano habría de servir para continuarlas.

${ }_{25}$ Acuerdo del concejo sobre como trajo la traza maese Enrique y lo que se mandó y asentó sobre ello, 28 de febrero de 1546, AMA, libro de acuerdos de 1543, caja 4, siglo XVI, fol. $207 \mathrm{r}$. 
El maestro recibiría 5.000 maravedís de salario por cada un año de los que anduviere en la obra, cantidad a la que se sumarían otros tres reales por cada día que se ocupare en la obra como tal maestro ${ }^{26}$.

Las autoridades de la villa continuaron adoptando decisiones sobre la fábrica de la Madre de Dios en días posteriores, pero lo cierto es que éstas se vieron abocadas al fracaso por falta de medios económicos. En 1560 las obras volvían a estar paradas y, lo que es más grave, habían avanzado muy poco. Los trabajos se habían detenido porque las rentas que había consignado el concejo para construir la iglesia, concretamente el producto de tres dehesas, tuvieron que destinarlas a sufragar otros gastos. Ante la falta de recursos y la magnitud del proyecto original, que hacía previsible que no pudiera terminarse en muchos años, los miembros del ayuntamiento decidieron construir un edificio provisional dentro de lo que sería la nave central de la iglesia para que se pudiera oficiar misa mientras se terminaba la obra principal. El proyecto despertó la oposición del fiscal de la orden de Calatrava que remitió un escrito al Consejo de Órdenes solicitando la paralización de las obras, pero las diligencias que se realizaron por orden del Consejo dieron el resultado opuesto al esperado por el fiscal. El propio juez de residencia veía con buenos ojos el proyecto, por lo que al final la iglesia provisional se terminó. Las diligencias que se realizaron a petición del Consejo resultan interesantes porque nos permiten conocer varios aspectos de la obra principal. Por la declaración de Miguel de Lerma, tesorero de la Mesa Maestral de Calatrava, sabemos que los pilares torales comenzaron a levantarse en torno a 1559 gracias, precisamente, a su apoyo económico ${ }^{27}$. Además, las diligencias incluyen varias referencias sobre dos maestros que trabajaron en las obras: Vicente Álvarez y el propio Juan Navarro. Vicente Álvarez trabajó, según sus propias palabras, tanto en la fábrica principal como en el edificio provisional. Juan Navarro, por su parte, estaba realizando en esos momentos los pilares torales. Según distintos testimonios, el cantero había cobrado unos 11.000 maravedís por el trabajo que había realizado y todavía se le debían otros 3.500 más $^{28}$.

Seis años después, la situación económica que padecía la fábrica seguía siendo la misma; por eso, los miembros del concejo de Almagro enviaron una petición al Consejo de Órdenes para conseguir fondos con los que, entre otras cosas, proseguir la obra de la iglesia. Tras realizar las diligencias oportunas y conocer el estado en el que se hallaba la fábrica, los miembros del Consejo concedieron doçientos ducados por diez años para la yglesia de la Madre de Dios, dictaminando además que con eso y con lo que ellos saquen de limosnas den traça como la yglesia se acabe porque no les $h(a n)$ de dar mas $^{29}$. Sin embargo, la cantidad fue claramente insuficiente por lo que en 1581 las autoridades de la villa volvieron a realizar gestiones para obtener más fondos con los que proseguir las obras. La declaración del rector de la parroquia, frey Alonso Martínez, incluida dentro de las diligencias, nos permite conocer de primera mano la situación en la que se hallaban. Según sus propias palabras en el hedifiçio della solamente de presente ay fecho la muralla de la mytad de la dicha yglesia y ansi se puede ver por vista de ojos la qual dicha yglessia esta por

\footnotetext{
${ }^{26}$ Enrique Egas recibiría estos 5.000 maravedís porque tenga cargo de la dicha obra y dar su pareçer en ella y traçar y hazer todo lo neçesario como tal maestro. Asiento con maese Enrique para la obra de la iglesia nueva, 4 de marzo de 1546, AMA, libro de acuerdos de 1543, caja 4, siglo XVI, fol. 209r.

${ }_{27}^{27}$ Miguel de Lerma precisó que el año pasado dio quarenta o quarenta y un myll maravedis para començar a levantar los dos pilares torales. Declaración de Miguel de Lerma contenida en la información realizada a petición del procurador del concejo de Almagro, 17 de agosto de 1560, AHN, Órdenes Militares, Archivo Histórico de Toledo, legajo 43605, sf.

${ }_{28}^{28}$ Información realizada a petición del procurador del concejo de Almagro, 16 y 17 de agosto de 1560, AHN, Órdenes Militares, Archivo Histórico de Toledo, legajo 43605, sf.

${ }^{29}$ Anotación con la decisión adoptada por el Consejo de Órdenes incluida en las diligencias realizadas a petición del concejo de Almagro sobre la financiación de la obra de Madre de Dios, sin fecha, AHN, Órdenes Militares, Archivo Histórico de Toledo, legajo 43593, sf.
} 
cuvrir. Su testimonio, además, deja claro que no solo era necesario realizar las bóvedas, porque no ay cosa cubierta del hedificio nuevo prinçipal, sino que también había que hacer dentro della los pilares de piedra que son menester para que carguen los arcos porques yglesia de tres naves ${ }^{30}$. Queda claro que la fábrica no había avanzado prácticamente nada en cincuenta años, una situación que nos obliga a plantearnos hasta qué punto el edificio que podemos contemplar en la actualidad, y que terminó levantándose entre finales del siglo XVI y principios del XVII, responde al modelo diseñado por Enrique Egas el Mozo, aunque éste es un tema para otro trabajo.

\section{Otros maestros del círculo toledano: Pedro de Hita y Alonso de Escuderos}

Los Egas y Lorenzo de Balbás no fueron los únicos maestros relacionados con Toledo que trabajaron en la comarca, también hemos documentado la presencia de otros dos que, de una manera u otra, estaban vinculados a ese importante foco artístico: Pedro de Hita y Alonso de Escuderos. Pedro de Hita, vecino de Toledo, fue el maestro encargado de comenzar la reforma de la iglesia de Almodóvar del Campo. La decisión de ampliar el edificio partió del propio concejo y se tomó entre 1527 y 1528 . Fue en torno a esos años cuando con voluntad de todo el pueblo estando en ayuntamiento y en presençia del liçençiado Aviles que a la sazon era juez de rresidençia en esta provinçia se acordo de alargar la dicha yglesia e agrandalla porque no cabia la mytad de la gente ${ }^{31}$. La iglesia antigua, de la que aún se conserva el cuerpo, era un edificio de tres naves, la central más alta y ancha que las laterales, cubiertas con sendas armaduras de madera que todavía podemos contemplar. En palabras del propio maestro, el proyecto de ampliación incluía la construcción de quatro capillas y la torre; es decir, el ábside poligonal que remata la nave central y el primer tramo de cada una de las tres naves, espacios que se cierran mediante complejas bóvedas de crucería ${ }^{32}$. Pedro de Hita se comprometió a realizar la obra por 470.000 maravedís, cantidad en la que se incluían las manos de maestro y peones y todos los materiales, que también corrían por cuenta del maestro. Sin embargo, el proyecto sobrepasaba con mucho la capacidad económica de la fábrica y los problemas de financiación salieron a la luz en 1536. En esos momentos ya se había levantado más de la mitad de la torre y los muros o adarves de las capillas tenían quatro estados de honbre poco mas o menos. Pedro de Hita, por su parte, había recibido 220.000 maravedís, por lo que aún debían darle otros 250.000, pero la iglesia carecía de fondos. Con la intención de obtener el dinero que necesitaban para terminar la obra, los miembros del concejo decidieron realizar un repartimiento entre los vecinos de la localidad o una sisa en los mantenimientos de la villa y remitieron una petición al Consejo de Órdenes para conseguir el permiso necesario. Los miembros del Consejo accedieron a la petición ${ }^{33}$ pero, a juzgar por el estado en que se hallaba la fábrica, lo más probable

\footnotetext{
${ }^{30}$ Declaración de frey Alonso Martínez incluida en la probanza realizada a petición de Juan Gutiérrez de la Caballería, regidor de Almagro, 22 de febrero de 1581, AHN, Órdenes Militares, Archivo Histórico de Toledo, legajo 43112, sf.

${ }^{31}$ Juan de Villarreal y Aparicio Martín del Olmo, dos de los testigos que declararon durante las gestiones que se realizaron para obtener fondos con los que proseguir las obras, afirmaron que la ampliación había comenzado hacía ocho nueve años poco mas o menos. Información realizada a petición de Francisco Hernández, mayordomo de la parroquia de Almodovar del Campo, 3 de abril de 1536, AHN, Órdenes Militares, Archivo Histórico de Toledo, legajo 44515, sf.

32 Según varios testigos la torre no formaba parte del proyecto inicial sino que fue necesario levantar otra cuando se hundió la antigua como consecuencia de las obras.

${ }^{33}$ El expediente presenta una anotación con la decisión del Consejo concediendo licencia para repartir en quantia de dozientos y çinquenta mill maravedis para la obra de la yglesia. Anotación con la decisión adoptada por el Consejo de Órdenes incluida en las diligencias realizadas a petición del ayuntamiento de Almodovar del Campo para poder realizar un repartimiento entre los vecinos de la localidad, sin fecha, AHN, Órdenes Militares, Archivo histórico de Toledo, legajo 44515, sf.
} 
es que Pedro de Hita no llegase a terminar la obra y fuera sustituido por otro maestro, porque en 1537 ya había fallecido, según consta en la visita que se realizó ese mismo año a la parroquia de Puertollano. Como es lógico, en la reforma tuvieron que trabajar otros maestros bajo la dirección de Pedro de Hita. Desgraciadamente la documentación solo nos ofrece el nombre de uno de ellos. Se trata de Francisco Sánchez Harpado, maestro de albañilería y cantería vecino de Almagro que hizo ciertos arcos para las capillas.

La ampliación de la parroquia de Puertollano corrió a cargo de Alonso de Escuderos, maestro que era vecino de la localidad toledana de Yepes. La primera referencia a la obra aparece en la visita de 1537. Ese año los representantes de la Orden comprobaron que estaba construyéndose una nueva capilla en la iglesia muy honrrada e suntuosa. A juzgar por la terminología utilizada en la época lo que estaba levantándose era la nueva cabecera que estaba rematada por el típico ábside poligonal de tres lados. Alonso de Escuderos se comprometió a realizar la obra por 165.000 maravedís pero los problemas económicos no tardaron en surgir. El maestro levantó los adarves della (capilla) e labro la mayor parte de la piedra para los arcos e cruzeria, pero la cantidad en la que se había concertado la obra resultaba insuficiente para terminarla. Los oficiales del concejo pagaron la cantidad estipulada y como pareçio que la obra mereçia mas del dicho preçio el dicho Alonso de Escuderos traxo una provisyon del Consejo Rreal de su magestad por la qual mandava al governador desta provinçia que avida ynformaçion que (sic.) el dicho Alonso de Escuderos estava agraviado le mandase gratificar ${ }^{34}$. El gobernador dejó el tema en manos del rector de la parroquia y de otras tres personas: Pedro de Hita, el maestro que había comenzado la reforma de la parroquia de Almodóvar, y dos vecinos de Puertollano, Juan de Malagón y el licenciado Martín Alonso. Por desgracia, la valoración no pudo realizarse porque tanto el licenciado como Pedro de Hita murieron antes de hacerla. La situación se agravó aún más con la muerte del propio Alonso de Escuderos, que falleció unos días antes de la llegada de los visitadores. Ante esta situación, y teniendo en cuenta que los fiadores del maestro eran pobres de manera que no ay de donde se pueda acabar de hazer la dicha obra sy no es de los propios bienes de la dicha yglesya, el párroco y los miembros del concejo solicitaron permiso a los visitadores para que puedan labrar e mandar pagar lo que fuere menester hasta acabar la dicha capilla. En su petición, afirmaban que la obra estaba muy avanzada, ya que estaban hechos e çerrados los dichos arcos y cruzeria y hecho mucha parte del caxco, y además argumentaban que lo realizado corría peligro porque al ser prinçipio de ynvierno todo se hundiria e desharia con el agua ${ }^{35}$. Los visitadores accedieron a la petición y, aunque no tenemos más noticias sobre los maestros que trabajaron en la fábrica de la iglesia, sabemos que el cuerpo del edificio ya estaba terminado en $1577^{36}$.

\section{Los maestros de origen vizcaíno}

El panorama arquitectónico de la comarca quedaría incompleto si no hiciéramos referencia a una cuadrilla de canteros de origen vizcaíno dirigida por Martín de Zalvilla (o Calvilla) y de la

${ }^{34}$ Visita realizada a la parroquia de Santa María de Puertollano por frey Rodrigo Enriquez y frey Alonso Ortiz, 24 de octubre 1537, AHN, Órdenes Militares, legajo 6078, exp. 5, fol. 194r. José Domingo Delgado Bedmar ya utilizó este documento, pero consideró erróneamente que la construcción en cuestión era una capilla lateral y no la cabecera de la iglesia. La implicación de los miembros del concejo en la obra es uno de los datos a tener en cuenta que corroboraría nuestra teoría. delgado BedMar, 1990: 43.

${ }_{35}$ Visita realizada a la parroquia de Santa María de Puertollano por frey Rodrigo Enriquez y frey Alonso Ortiz, 24 de octubre 1537, AHN, Órdenes Militares, legajo 6078, exp. 5, fol. 194v.

${ }^{36}$ Visita realizada a la parroquia de Santa María de Puertollano por frey Hernando Osorio y frey Jerónimo Treviño, 1577, AHN, Órdenes Militares, legajo 6083, exp. 12, sf.

Arch. esp. arte, LXXXVI, 341, ENERO-MARZO 2013, 15-28, ISSN: 0004-0428 
que formaban parte Martín de Arteta y Domingo de Uberoaga, oficiales que se encargaron de continuar las obras iniciadas por el primero. No sabemos cuándo llegaron estos maestros a la zona, pero de los datos que tenemos se deduce que su presencia estaría relacionada con la fábrica de la iglesia de Santa María de Ciudad Real (actual basílica catedral de la capital), y más concretamente con la construcción de su antigua torre, y que una vez aquí extendieron su radio de acción a los pueblos de la zona, realizando distintas intervenciones en las parroquias de Alcolea, Agudo, Miguelturra y Picón.

Sin duda, la ampliación de la parroquia de Miguelturra es la obra más importante y la mejor documentada. Las diligencias para construir una iglesia de mayores dimensiones se iniciaron a mediados de siglo. Los visitadores de la Orden de Calatrava, frey Tello de Guzmán y frey Pedro de Merlo, tuvieron ocasión de comprobar las reducidas dimensiones del viejo edificio e iniciaron las gestiones para ampliar la iglesia. Los representantes de la orden no solo concedieron la licencia necesaria para construir el nuevo edificio, sino que también se encargaron de buscar un maestro apropiado que realizase la traza del mismo. A la hora de elegir al maestro en cuestión, frey Tello de Guzmán y frey Pedro de Merlo no dirigieron sus miradas a la localidad de Almagro, sino que pensaron en el núcleo de población más próximo a Miguelturra, Ciudad Real. Los visitadores debían saber que en esos momentos se estaba construyendo la primitiva torre de la parroquia de Santa María y que, por tanto, podrían encontrar en la localidad oficiales cualificados. Impulsados probablemente por esta razón decidieron llamar al maestro que estaba realizando la obra. El hombre en cuestión era Martín de Zalvilla que acudió a Miguelturra acompañado de uno de sus oficiales, Martín de Arteta. El maestro estuvo hablando con los visitadores sobre la construcción de una nueva capilla mayor, o cabeçera de iglesia como se la denomina en la documentación ${ }^{37}$. Sin embargo, las obras no comenzaron de inmediato debido a la falta de dinero, sino que se retrasaron dos o tres años. Al cabo de ese tiempo el dicho Martin de Calvilla volvió a la localidad acompañado de Arteta para abrir las çanjas e sacaron los çimientos de la dicha capilla; pero, una vez iniciadas, las obras volvieron a pararse porque las exiguas rentas de la iglesia, que contaba básicamente con las primicias para costear los gastos de su fábrica, y las aportaciones de los vecinos no eran suficientes para continuar el proyecto. Ante esta situación, el párroco de la localidad, Francisco de Cisneros, decidió solicitar ayuda económica al Consejo de Órdenes. Las gestiones que se realizaron para recabar información sobre el proyecto se desarrollaron entre finales de 1565 y principios de 1566. En esas fechas Martín de Zalvilla ya había muerto; por eso, el gobernador del Campo de Calatrava mandó llamar a Martín de Arteta y Domingo de Uberoaga para tasar la obra de la iglesia. Los maestros, que ya habían declarado como testigos propuestos por el párroco de Miguelturra, determinaron que para terminar el ochavo y la capilla que se habían iniciado eran necesarios 654.440 maravedís, y para construir el resto del cuerpo de la iglesia, que debía constar de otros tres tramos o capillas, serían menester más de 1.800 .000 maravedís ${ }^{38}$. No hemos encontrado ninguna referencia en torno al desarrollo de las obras pero, si tenemos en cuenta el aspecto que presenta el edificio en la actualidad, podemos afirmar que sólo se terminó el ábside y el primer tramo de la nave, cerrados mediante bóvedas de crucería. El resto del edificio, que está cubierto por una bóveda de medio cañón con lunetos, debe su aspecto a una intervención posterior.

${ }^{37}$ Declaración de Martín de Arteta incluida en la información realizada por Francisco de Cisneros, 7 de febrero de 1566, AHN, Órdenes Militares, Archivo Histórico de Toledo, legajo 38379, sf.

${ }_{38}$ Tasación de la obra de la parroquia de Miguelturra realizada por Martín de Arteta y Domingo de Uberoaga, 20 de febrero de 1566, AHN, Órdenes Militares, Archivo Histórico de Toledo, legajo 38379, sf. 


\section{APÉNDICE DOCUMENTAL}

Traslado de una carta remitida por Juan de Inestrosa a Antón Egas. AHN., OOMM., Archivo histórico de Toledo, legajo 44344.

Muy virtuoso señor yo estoy sospechoso de la çanja y çimyento que se a hecho en Almagro en el espital (sic.) que se a herrado diziendo los que dizen que son maestros que si fuera por donde vos señor deziades por vuestra traça quel hastial que va por el camino no podria venyr por el sino a dar a mitad de las guertas e quedavase muncho perdido con el camino por manera que para tomar el çimyento por el camino echaron el çimyento que yva a San Sabastian mas de çinco pasos metidos en la casa questava enhiesta e quyeren desir que agora va en quadra yo mande que no obrase mas alli del hazer aquel çimyento hasta que señor fuesedes ynformado dello pidos señor por merçed que si en la memoria teneys esto que aqui escrivo aya vuestra rrespuesta.

Ansymesmo sabed señor que os pedi por merçed me diesedes un maestro de vuestra mano para que labrase y ordenase porque tal obra como aquella hazella con maestros caseros abria en lo mas el peligro que agora ay en lo menos como señor os escrivo ansi que en todo os pido señor por merçed que proveays y tengays por hija vuestra aquella obra Nuestro Señor vuestra virtuosa persona y casa guarde y acreçiente como señor deseays de Ginalarife a diez e seys de agosto a lo que señor mandaredes. Juan de Hinestrosa.

Traslado de una carta remitida por Antón Egas a Enrique Egas el Mozo. AHN., OOMM., Archivo histórico de Toledo, legajo 44344.

Señor sobrino ya creo que aveys sabido como plugo a Nuestro Señor de llevar a Balbas que tenya la obra del monesterio e ospital de Almagro e los señores disponedores me llamaron por mandado del Consejo para dar horden como la obra se haga e quisyeron mi paresçer de que persona podra tener cargo de la obra e yo les he dicho la persona que soys e lo que sabeys e como podreys dar quenta de aquella obra e de otra mayor e ellos sabiendo ser vos hijo de maestre Enrrique e por lo que yo les he dicho aunque no os conosçen avran por bien de vos dar cargo de la obra e mejoraros en el partido que davan a Balbas que hera tres rreales cada dia e dos moços e por rrazon de una casa que le mandaron en que morase le dieron diez myll maravedis una vez yo tengo platicado e asentado que os den a vos diez mill maravedis de salario en cada un año e los tres rreales cada dia de trabajo e dos moços con los jornales que meresçieren e mas en el mesmo monesterio una o dos pieças en que podays estar vos e vuestra jente sy las quisyeredes. A vuestro padre e a mi nos paresçe que es rrazonable partido porque la obra es buena e donde podeys mostrar lo que sabes e la villa tiene grandes comarcas e se levantan obras que todo verna a vuestra mano sera bien que si podays venir os vengays luego e syno escrivays vuestro paresçer e para quando verneys que bien podeys creher que no faltan golosos para la obra e porque vuestro padre os escribe çeso. Nuestro Señor vuestra muy honrrada persona guarde de Toledo a ocho de junio de myll e quinientos e treynta años a lo que señor mandaredes Anton Egas (...) A mi señor sobrino Enrrique Egas en Alhama.

\section{BIBLIOGRAFÍA}

Azcárate Ristori, José María de, "Datos sobre las construcciones en el Priorato de Uclés durante la primera mitad del siglo XVI", en Boletín del Seminario de Estudios de Arte y Arqueología, Tomo 25, 1959.

Barranquero Contento, José Javier, "Maestros y canteros en las obras del monasterio de Nuestra Señora de

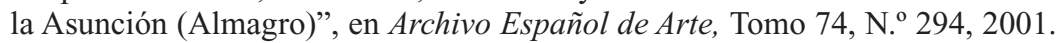

Barranquero Contento, José Javier, Conventos de la provincia de Ciudad Real. Devoción y clero regular, Ciudad Real, 2003.

Delgado Bedmar, José Domingo, La iglesia de la Asunción de Puertollano, Ciudad Real, 1990.

Galiano y Ortega, Federico, Documentos para la historia de Almagro, Ciudad Real, 2004 (edición facsímil de la de 1894).

Molina Chamizo, Pilar, De la fortaleza al templo. Arquitectura religiosa de la orden de Santiago en la provincia de Ciudad Real, Ciudad Real, 2006.

Sainz Magaña, Elena y Herrera Maldonado, Enrique, “Arte Moderno”, en Ciudad Real y su provincia, Sevilla 1996-97.

Fecha de recepción: 12-I-2011

Fecha de aceptación: 3-IV-2011

Arch. esp. arte, LXXXVI, 341, ENERO-MARZO 2013, 15-28, ISSN: 0004-0428 